\title{
O significado do sim para a família no processo de doação de órgãos
}

RESUMO | Objetivo: Conhecer o processo de decisão da família na doação de órgãos e seu significado. Método: pesquisa descritiva de abordagem qualitativa e natureza básica. Coletaram-se dados após aprovação do conselho de ética conforme o parecer de número 2.212.058, CAAE: 71403117.4.0000.0120, por meio de análise documental dos potenciais doadores no período de 2015 e 2016 e, em seguida, entrevistaram-se oito famílias que disseram sim para a doação de órgãos, realizando-se entrevista semiestruturada cujas respostas foram transcritas, analisadas e categorizadas, segundo análise temática. Resultados: a doação assume vários significados, entre eles, a continuidade da vida por meio do amor ao outro e respeito à vontade do familiar. Conclusão: O estudo permitiu, em seu percurso, compreender que a dor e o sofrimento fazem parte de todo o processo de hospitalização do familiar. Contudo, tratando-se de uma decisão tão delicada, a efetividade se dá, principalmente, ao conhecer o desejo do familiar e ao tocar o coração das pessoas.

Palavras-chaves: transplante de órgãos; família; legislação.

ABSTRACT | Objective: To know the decision process of the family in the donation of organs and their meaning. Method: descriptive research of qualitative approach and basic nature. Data were collected after approval by the ethics board according to record number 2.212.058, CAAE: 71402117.4.0000.0120, through document analysis of potential donors in the period of 2015 and 2016, followed by 8 families Who Said yes to organ donation through a semi-structured interview, transcribed, analyzed and categorized according to thematic analysis. Results: the donation assumes several meanings, among them continuity of life through Love of the other and respect the Will of the family. Conclusion: The study allowed us to understand that pain and suffering are part of the entire hospitalization process of the relative. But when it comes to such a delicate decision, effectiveness is mainly due to knowing the family's desire and touching people's hearts.

Keywords: organ transplantation; family; legislation.

RESUMEN | Objetivo: Conocer el proceso de decisión de la família em la donación de órganos y su significado. Método: investigación descriptiva de enfoque cualitativo y de naturaleza básica. Se recogió datos después de la aptobación Del consejo de ética según el dictamen de numero 2.212.058, CAAE: 71402117.4.0000.0120, a través Del análisis documental de los potenciales donantes em el período de 2015 y 2016, luego se entrevistó a 8 familias que dijeron sí para la donación de órganos a través de entrevista semiestructurada, transcriptas, analizadas y categorizadas, según el análisis temático. Resultados: la donación asume varios significados, entre ellos la continuidad de la vida por médio del amor al otro y respeto a la voluntad del familiar. Conclusión: El estúdio permitió em su recorrido comprender que el dolor y el sufrimiento forman parte de todo el proceso de hospitalización del familiar. Pero tratándose de una decisión tan delicada, la efectividad se da, principalmente, al conocer el deseo del familiar y al tocar el corazón de las personas. Descriptores: trasplante de órganos; la familia; legislación.

\section{Juliana Vieira de Araujo Sandri}

Enfermeira. Doutora em Enfermagem. Docente do Curso de Graduação em Enfermagem e do Programa de Mestrado Profissional em Saúde e Gestão do Trabalho da Universidade do Vale do Itajaí. Universidade do Vale do Itajaí -SC.

\section{Elisandra Alves Kuse}

Enfermeira. Especialista em Urgência, Emergência e Trauma. Mestra em Saúde e Gestão do Trabalho da Universidade do Vale do Itajaí. Universidade do Vale do Itajaí - SC.

Recebido em: 15/05/2018

Aprovado em: 27/05/2019

INTRODUÇÃO

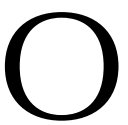

Brasil dispõe do maior programa público de transplantes do mundo, que vem crescendo significativamente nos últimos anos, embora ainda seja insuficiente, dado o número de pessoas que estão na fila de espera ${ }^{1}$. O transplante é um procedimento cirúrgico que consiste na reposição de um órgão ou tecido de uma pessoa doente (receptor) por outro órgão ou tecido normal de um doador, podendo ser em vida ou post mortem. Este último é mais frequente e o paciente deve ser diagnosticado com morte encefálica para seus órgãos estarem disponíveis à transplantação², se tornando um potencial doador.
Entende-se por potencial doador de órgãos e tecidos para transplantes toda pessoa que esteja em coma aperceptivo e arreativo e que não seja diagnosticada com alguma doença que inviabilize a doação ${ }^{3}$.

Os transplantes de órgãos se iniciaram no país na década de 1960, mas somente em 1997 foram regulamentados em todo o território nacional, por meio da Lei no 9.434/1997 e seu Decreto no 2.2687 , prevalecendo a necessidade de consentimento baseado em autorização da família por escrito ${ }^{4,5}$.

Para que se efetivassem as etapas do processo de doação de órgãos foi necessária a criação do Sistema Nacional de Transplantes, coordenado 
pelo Ministério da Saúde, e das Centrais de Notificação, Captação e Distribuição de Órgãos para os estados brasileiros, criando-se, assim, uma lista única para a distribuição de órgãos e tecidos doados 5 .

No Brasil, a recusa familiar ainda é alta. De acordo com dados divulgados pela Associação Brasileira de Transplantes de Órgãos (ABTO) ${ }^{6}$, em 2016, a recusa familiar foi de $44 \%$, ou seja, em cada grupo de 100 famílias de possíveis doares, 44 recusam a doação. Para o nefrologista José Osmar Medina Pestana citado por Ziegler ${ }^{7}$, a principal justificativa das famílias para não doar órgãos de seus entes falecidos é o fato de nunca terem conversado sobre o desejo de doação. Um fator decisivo para a diminuição da recusa familiar nesse momento de consternação é a capacitação dos profissionais responsáveis pela abordagem da família ${ }^{8}$.

Este artigo abrange um dos objetivos da dissertação do Mestrado de Saúde e Gestão do Trabalho da Universidade do Vale do Itajaí, intitulada: 'A família como centro do processo de decisão para a doação de órgãos e tecidos', no tocante a relatar o significado da doação para a família com relação ao processo de decisão para doação de órgãos.

Em 2016, o Brasil registrou o maior número de doadores efetivos da história: 2.983 no total. O número representa uma taxa de 14,6 pmp (por milhão da população), 5\% maior em comparação a 2015, porém menor do que a prevista, que era de 15,1 pmp $^{6}$.

A partir dessas considerações, o estudo se propôs a responder a seguinte questão: Como ocorreu o processo de decisão da família quanto à doação de órgãos? Sendo assim, tecemos o objetivo geral de conhecer o processo de decisão da família na doação de órgãos e seu significado. Neste artigo está apresentado um dos objetivos específicos que é o de relatar o significado, para a família, do processo de decisão para a doação de órgãos, através da categoria temática - O significado para a família em consentir a doação de órgãos.

\section{MÉTODO}

Tratou-se de uma pesquisa descritiva de abordagem qualitativa e natureza básica. A pesquisa de natureza básica possibilita o conhecimento do objeto de estudo em relação com o meio do qual ele faz parte. A abordagem qualitativa foi a partir da análise temática, a qual consiste basicamente em identificar os núcleos de sentido que compõem uma comunicação e cuja presença ou frequência tenham algum significado para o objeto analítico visado. Realizada em três etapas: pré-análise, exploração do material incluindo o tratamento dos resultados e sua interpretação.

A pesquisa foi realizada em um Hospital Geral que tem a Comissão Intra-hospitalar de Doação de Órgãos e Tecidos para Transplantes (CIHDOTT) atuante, de referência da região de saúde da Foz do Rio Itajaí-açu no estado de Santa Catarina. Esse hospital conta com 350 leitos distribuídos em dezesseis unidades de internação para atender pacientes da cidade e regiões próximas nas diversas especialidades médicas.

Os participantes incluídos na pesquisa foram familiares residentes no município de Itajaí (SC) que consentiram a doação de órgãos e tecidos em 2015 e 2016, das dez famílias foi realizado a entrevista com oito dessas, sendo que duas não foi possível localizar pelo endereço residencial disponível. Estabeleceu-se, para esta investigação, que se houvesse mais de um membro da família que manifestasse interesse em responder os questionamentos e que satisfizesse os critérios de inclusão, seria dada a oportunidade para todos participarem ou, se fosse da vontade deles, apenas um participaria, por livre escolha de seus membros.

Adotaram-se os seguintes critérios de inclusão: adultos pertencentes às famílias dos potenciais doadores que consentiram a doação de órgãos na instituição hospitalar de referência e alta complexidade nos últimos três anos, residentes no município de Itajaí (SC) e que aceitassem participar da pesquisa.

Os critérios de exclusão foram: adultos pertencentes às famílias dos potenciais doadores que disseram não à doação de órgãos e tecidos ou a famílias que disseram sim à doação, porém, a data do óbito igual ou inferior a seis meses, familiares que consentiram, com data de óbito superior a seis meses, mas não eram residentes no município de Itajaí-SC e os que não aceitassem participar da pesquisa.

A pesquisa foi viável porque a instituição hospitalar escolhida para aplicação da coleta de dados é referência para a região da Foz do Rio Itajaí-açu com relação à captação de órgãos e de tecidos em Santa Catarina. Ela possui, desde 2003, a CIHDOTT, formada por quatro enfermeiras e um médico coordenador.

A coleta de dados da pesquisa foi realizada em agosto e setembro de 2017, inicialmente, por meio de análise documental. Os documentos analisados foram os prontuários da $\mathrm{CIH}$ DOTT, nos quais se buscou o total de potenciais doadores em 2015 a 2016. Durante a análise de documentos foram verificados a idade do doador, o sexo, a causa do óbito e a decisão da família. Já as entrevistas semiestruturada ocorreram com oito famílias que consentiram a doação de órgãos nesse período, residentes na cidade de Itajaí (SC) e, data do óbito superior a seis meses. As respostas das entrevistas foram gravadas e transcritas e, os dados obtidos foram estudados por meio da análise temática.

Participaram da entrevista os familiares que decidiram legalmente pela doação de órgãos e outros membros da família que estavam presentes e vivenciaram o processo junto com o familiar selecionado.

A investigação iniciou após a auto- 
rização da direção da instituição hospitalar e aprovação do Comitê de Ética da Universidade do Vale do Itajaí (Univali), em 10 de agosto de 2017, conforme o parecer de número 2.212.058, CAAE: 71403117.4.0000.0120, sendo consideradas todas as exigências contidas na resolução 466/12, que rege as pesquisas com seres humanos.

\section{RESULTADOS}

Com referência ao perfil dos entrevistados que disseram 'sim' a doação de órgãos apresentados na tabela 1 mostra que, houve predomínio dos fiIhos $(37,5 \%)$ na autorização da doação de órgãos, dentro da faixa etária de 29 a 38 anos $(33,3 \%)$, a maioria do sexo feminino $(58,3 \%)$.

O perfil dos potenciais doadores (2015 e 2016) apontado na tabela 2, revela que a maioria era do sexo masculino $(62,5 \%)$, com idade entre 39 e 68 anos $(75 \%)$, sendo que a faixa etária de 59 a 68 anos foi a mais evidenciada $(27,1 \%)$. O acidente vascular encefálico foi a mais importante causa de morte, acometendo 33 sujeitos $(68,7 \%)$. Quanto ao período do óbito, o número de casos foi um pouco maior no segundo semestre, com 26 registros $(54,2 \%)$ nos dois anos. De todos os potenciais doadores identificados, 24 tiveram seus órgãos doados, tornando-se doadores efetivos $(50 \%)$. Dos 24 doadores efetivos, $10(41,66 \%$ do total) tinham como procedência informada Itajaí e $14(58,33 \%)$, outras localidades próximas a esse município.

A análise das entrevistas resultou, dentre outros achados, a categoria temática - O significado para a família em consentir a doação de órgãos, com as suas duas subcategorias descritas a seguir:

Ficou explícito nos relatos dos entrevistados que, para todas as famílias, o significado da doação tinha um elemento em comum: o desejo consciente de oferecer a uma pessoa a oportunidade de dar continuidade à vida com

Tabela 1. Identificação dos familiares que autorizaram a doação em 2015 e 2016 Itajai (SC), 2017.

\begin{tabular}{|c|c|c|c|c|c|c|}
\hline \multirow[t]{2}{*}{ Dados de Identificação } & \multicolumn{2}{|c|}{$\begin{array}{c}\text { Ano } 2015 \\
(\mathrm{~N}=25)\end{array}$} & \multicolumn{2}{|c|}{$\begin{array}{c}\text { Ano } 2016 \\
(\mathrm{~N}=23)\end{array}$} & \multicolumn{2}{|c|}{$\begin{array}{l}\text { TOTAL } \\
(\mathrm{N}=48)\end{array}$} \\
\hline & $\mathrm{N}$ & $\%$ & $\mathrm{~N}$ & $\%$ & $\mathrm{~N}$ & $\%$ \\
\hline \multicolumn{7}{|l|}{ Sexo } \\
\hline Masculino & 05 & 50 & 05 & 35,7 & 10 & 41,7 \\
\hline Feminino & 05 & 50 & 09 & 64,3 & 14 & 58,3 \\
\hline \multicolumn{7}{|l|}{ Idade } \\
\hline 18 a 28 anos & 02 & 20 & 01 & 7,1 & 03 & 12,5 \\
\hline 29 a 38 anos & 04 & 40 & 04 & 28,6 & 08 & 33,3 \\
\hline 39 a 48 anos & 02 & 20 & 05 & 35,7 & 07 & 29,2 \\
\hline 49 a 58 anos & 02 & 20 & 01 & 7,1 & 03 & 12,5 \\
\hline 59 a 68 anos & 00 & 0,0 & 03 & 21,4 & 03 & 12,5 \\
\hline \multicolumn{7}{|l|}{ Parentesco } \\
\hline Filhos & 06 & 60 & 03 & 21,4 & 09 & 37,5 \\
\hline Pais & 02 & 20 & 02 & 14,3 & 04 & 16,7 \\
\hline Cônjuge & 02 & 20 & 03 & 21,4 & 05 & 20,8 \\
\hline Irmãos & 00 & 00 & 06 & 42,9 & 06 & 25 \\
\hline
\end{tabular}

Tabela 2. Identificação dos potenciais doadores em 2015 e 2016 - Itajaí (SC), 2017.

\begin{tabular}{|c|c|c|c|c|c|c|}
\hline \multirow[t]{2}{*}{ Dados de Identificação } & \multicolumn{2}{|c|}{$\begin{array}{c}\text { Ano } 2015 \\
(\mathrm{~N}=25)\end{array}$} & \multicolumn{2}{|c|}{$\begin{array}{c}\text { Ano } 2016 \\
(\mathrm{~N}=23)\end{array}$} & \multicolumn{2}{|c|}{$\begin{array}{l}\text { TOTAL } \\
(\mathrm{N}=48)\end{array}$} \\
\hline & $\mathrm{N}$ & $\%$ & N & $\%$ & N & $\%$ \\
\hline \multicolumn{7}{|l|}{ Causa da morte } \\
\hline Acidente vascular encefálico & 18 & 72 & 15 & 65,2 & 33 & 68,7 \\
\hline Traumatismo Encefálico & 03 & 12 & 03 & 13 & 06 & 12,5 \\
\hline Tumor cerebral & 01 & 4 & 02 & 8,7 & 03 & 6,2 \\
\hline Neurotoxoplasmose & 01 & 4 & 00 & 00 & 01 & 2,1 \\
\hline Encefalopatia idiopática & 01 & 4 & 02 & 8,7 & 03 & 6,2 \\
\hline Outros & 01 & 4 & 01 & 4,3 & 02 & 4,2 \\
\hline \multicolumn{7}{|l|}{ Data óbito } \\
\hline Fevereiro a junho & 11 & 44 & 11 & 47,8 & 22 & 45,8 \\
\hline Julho a dezembro & 14 & 56 & 12 & 52,2 & 26 & 54,2 \\
\hline \multicolumn{7}{|l|}{ Residência } \\
\hline Itajaí & 03 & 12,5 & 07 & 29,16 & 10 & 41,7 \\
\hline Outros & 07 & 29,16 & 07 & 29,16 & 14 & 58,3 \\
\hline
\end{tabular}

sua atitude de consentimento. Os sentimentos de felicidade, solidariedade, amor pelo próximo e gratidão apareceram na subcategoria continuidade da vida por meio do amor ao outro. Durante os encontros, quando questionados a respeito do que significou a doação, a expressão facial e as palavras ditas, assim como os sentimentos anteriormente citados, surgiam de forma terna e com tom de serenidade.
As narrativas de F4 e F7 elucidam a motivação dos familiares para decidir pela doação e expressam o significado para as famílias nesse processo.

Naquela situação o que a gente podia fazer de melhor para o mundo, para outras pessoas era fazer a doação, não restou nenhuma dúvida para a gente. [...] na verdade, assim, 
eu acho que todos devem pensar assim, quando tu dizes o sim de alguma forma está ajudando alguém, apesar da perda é um sentimento muito agradável de poder estar ajudando (F4).

É um sentimento assim de alegria, felicidade. Eu acho que as pessoas têm que fazer isso [...] é um pedacinho teu para aquele que precisa, tem que ter amor pelas pessoas, ainda mais não sabendo nem quem é esse é o amor ao próximo, assim que eu vejo, fiz isso pelo meu marido, eu passei para outra pessoa e o amor continua por aí (F7).

A possibilidade de dar um pedaço do familiar a outra pessoa, mesmo sem saber a quem, por meio da doação, também apareceu nos relatos como fator de motivação que traz significado à decisão. Os entrevistados expressaram que as famílias dos doadores imaginam uma forma de continuidade dessa vida em outro corpo. Externam esse significado as falas de F3, F6 e F7.

Para mim foi gratificante, porque apesar dele ter morrido cedo, é saber que ele fez uma coisa boa entendeu, e que ele está por aí, um pedaço dele, é assim que eu penso, um pedacinho dele, porque ele ajudou muitas pessoas (F3).

[...] saber que o órgão dela, um pedaço dela continua vivo em outra pessoa eu acho lindo, a gente queria muito saber quem é, mas valeu a pena (F6).

[...] alguém está enxergando de novo e os outros órgãos, a pessoa estava precisando e teve uma chance de estar vivendo [...] (F7).

Outro ponto incentivador que levou os familiares a aceitarem a doação é justamente porque, em algum mo- mento das relações familiares, houve diálogo sobre a temática, respeitando a vontade do familiar falecido, evidencia que o conhecimento do desejo influencia diretamente na decisão da família. Esse desejo conhecido e que foi respeitado foi relatado por dois entrevistados: F3 e F8.

A gente respeitou a vontade dele. Minha cunhada disse que ele gostaria de doar porque tipo um mês antes a gente conversou sobre isso (F3).

A gente conversava sobre o assunto em casa, até ele falava, tudo vai apodrecer, para mim não importa essa matéria aqui, foi por esse motivo que a gente chegava no assunto e ele era doador (F8).

\section{DISCUSSÃO}

Diante desse tema tão complexo como a doação de órgãos e tecidos, conhecer os fatores que motivaram as pessoas a realizar a doação se torna imprescindível, mesmo considerando inquestionável a grandeza do ato de doar. Motivação deriva de uma palavra latina que significa mover, sendo caracterizada como uma força que move o indivíduo a optar por caminhos de significados de satisfação e necessidades ${ }^{9}$.

Nessa perspectiva de contribuir com o bem da sociedade, outra palavra presente nos estudos relacionados à doação de órgãos e que também apareceu nesta pesquisa foi a solidariedade. Vergés10 define solidariedade como valor social, criado a partir da consciência de uma comunidade de interesses e, portanto, humanitário em si mesmo.

Realizar a doação assume inúmeros significados, como conforto à família e satisfação, sendo esses sentimentos muito importantes para a sociedade, porque significam um ato do bem para as outras pessoas. Ao relembrar o pro- cesso de perda e a decisão pela doação de órgãos, os familiares confirmaram que o fato de acontecer em um momento difícil para a família, a doação de órgãos pode trazer conforto, satisfação e significar, principalmente, fazer o bem a outra pessoa ${ }^{11}$.

Em um estudo realizado por Carva$\mathrm{Iho}^{12}$, os familiares entrevistados fizeram relatos semelhantes aos deste estudo. $\mathrm{O}$ 'sim' à doação representou a possibilidade de continuidade da vida de seus entes, mesmo que de outra forma.

Milhares de pessoas, inclusive crianças, são beneficiadas com transplantes, nos quais a chance de sucesso é alta. A taxa de doadores efetivos cresceu 14\%, atingindo 16,6 pmp (por milhão de população) em 2017. Entre os destaques está o estado de Santa Catarina (40,8 pmp) com aumento de $10,9 \%$, e o Paraná (38,0 pmp) com $26,2 \%$, sendo os únicos estados que ultrapassaram os 30 doadores pmp. Santa Catarina efetivou 50\% dos potenciais doadores ${ }^{13}$.

É sabido que muitos são os motivos alegados pelas famílias para recusa da doação de órgãos e entre eles está o desconhecimento do desejo do falecido. Entretanto, a literatura aponta situações em que familiares alegaram menor conflito em relação ao consentimento, como nas citações anteriores, por conhecerem previamente a vontade do doador. Nesse sentido, a família é vista como fundamental no processo de doação de órgãos, por esse único ato poder beneficiar diversas pessoas ${ }^{14}$.

É preciso ter a clareza que para ser um doador não é necessário deixar nada por escrito, e saber que a família tem a decisão final. Diante disse, reforça-se a importância de as pessoas comunicarem o desejo da doação aos seus familiares, uma vez que o conhecimento dessa vontade pode determinar a decisão final ${ }^{15}$.

Nesse aspecto, é essencial que essa informação seja conhecida, que a própria pessoa decida em vida sobre o 
destino dos seus órgãos e comunique previamente sua família, sendo que essa comunicação à família poderá prepará-la previamente para a autorização da doação ${ }^{16}$.

Para tanto, é discutido3 sobre a importância da divulgação do assunto nos meios de comunicação, com o intuito de incentivar as pessoas a manifestarem em vida o desejo de doar. Este ato simples é extremamente importante para definir a decisão familiar.

O conhecimento do desejo do familiar, aliado ao conhecimento sobre morte encefálica, é apenas um dentre os vários fatores que contribuem para a doação. O atendimento humanizado, o esclarecimento de dúvidas de forma objetiva, a destreza nas ações, promoção de confiança e empatia dos profissionais com a família possibili- tam um aumento significativo na probabilidade da doação de órgãos ${ }^{17}$.

\section{CONCLUSÃO}

O estudo permitiu, em seu percurso, compreender que a dor e o sofrimento fazem parte de todo o processo de hospitalização da família. Inclui desde a internação a confirmação de morte encefálica, finalizando com a tomada de decisão sobre a doação. Contudo, para todas as famílias o significado da doação teve um conceito em comum, o desejo consciente de poder oferecer a oportunidade de dar continuidade à vida através de sua atitude de consentimento e respeitar a vontade do seu ente falecido.

Ao relembrar o processo de perda e a decisão pela doação de órgãos, os familiares confirmaram que o fato de acontecer em um momento difícil para a família, a doação de órgãos trouxe conforto, satisfação e significou, principalmente, fazer o bem a outra pessoa.

Os dados também revelaram o excelente desempenho do Estado de Santa Catarina na efetivação da doação de órgãos, isto reforça a importância do diálogo sobre o tema na sociedade e mais intimamente dentro do seio familiar, já que o poder de decisão é da família.

Não há dúvida de que o acesso à informação é indispensável para facilitar e ampliar o entendimento do processo como um todo e, especialmente, conhecer a realidade atual. Mas, tratando-se de uma decisão tão delicada, a efetividade se dá, principalmente, ao conhecer o desejo do familiar e ao tocar o coração das pessoas.

\section{Referências}

1. De Mattia AL, Rocha AM, Freitas Filho JPA, Oliveira MG, Barbosa MH, Rodrigues MB. Análise das dificuldades no processo de doação de órgãos: uma revisão integrativa da literatura. Bioethikos 2010; 4(1):66-74.

2. Teixeira RK, Gonçalves TB, Silva JA. A intenção de doar órgãos é influenciada pelo conhecimento populacional sobre morte encefálica. Rev Bras Ter Intensiva [internet]. 2012 [acesso em 20 mar. 2017]:258-62. Disponível em: https://pdfs.semanticscholar.org/19d1/5d668b1024a3aec590f31dbc527e288ff77d.pdf

3. Freire ILS, Mendonça AEO, Dantas BAS, Silva MF, Gomes ATL, Torres GV. Processo de doação de órgãos e tecidos para transplante: reflexões sobre sua efetividade. Rev Enf UFPE [internet]. 2014 [acesso em 14 mar. 2018]; 8(7):2533-8. Disponível em: https://periodicos.ufpe.br/revistas/revistaenfermagem/article/vie w/9948

4. Brasil. Lei $n^{\circ} 9.434$, de 4 de fevereiro de 1997. Dispõe sobre a remoção de órgãos, tecidos e partes do corpo humano para fins de transplante, e dá outras providências [internet]. Diário Oficial da União. 5 fev. 1997 [acesso em 2 jan. 2017]. Disponível em: http://www.planalto.gov.br/ccivil_03/leis/ L9434.htm

5. Brasil. Decreto $n^{\circ} 2.268$, de 30 de junho de 1997. Regulamenta a Lei $n^{\circ}$ 9.434, de 4 de fevereiro de 1997, que sobre a remoção de órgãos, tecidos e partes do corpo humano para fins de transplante e tratamento, e dá outras providências [internet]. Diário Oficial da União. 1 jul. 1997 [acesso em 2 jan. 2017]. Disponível em: http://www.planalto.gov.br/ccivil_03/decreto/1997/D2268impressao.htm

6. ABTO - Associação Brasileira de Transplantes de Órgãos. Dados numéricos da doação de órgãos e transplantes realizados por estado e instituição no período: janeiro/setembro - 2016 [internet]. 2016 [acesso em 22 dez. 2016]. Disponível em: http://www.abto.org.br/abtov03/Upload/file/ RBT/2016/RBT20163t-let.pdf

7. Ziegler MF. $47 \%$ das famílias se recusam a doar órgão de parente com morte cerebral. IG [internet]. 24 mar. 2014 [acesso em 20 dez. 2016]. Disponível em: http://saude.ig.com.br/minhasaude/2014-03-24/47-das-familias-se-recusam-a-doar-orgao-de-parente-com-morte-cerebral.html
8. Maynard LOD, Lima IMSO, Lima YOR, Costa, EA. Os conflitos do consentimento acerca da doação de órgãos post mortem no Brasil. Rev Dir Sanit 2015; 16(3):122-44. 2016

9. Bergamini CW. Motivação. 3.ed. São Paulo: Atlas; 1993.

10. Vergés C. Injerencia - assistência - solidaridad. In: Tealdi JC, director. Diccionario latinoamericano de bioética. Bogotá: Universidad Nacional de Colombia/Unesco; 2008. p. 123-4.

11. Rossato GC, Girardon-Perlini NMO, Begnini D, Beuter M, Camponogara S, Flores CL. Doar ou não doar: a visão de familiares frente à doação de órgãos. Reme - Rev Min Enferm [internet]. 2017 [acesso em 3 abr. 2018];21:18. Disponível em: file:///C:/Users/Elis/Downloads/e1056\%20(2).pdf 12. Carvalho AL. Realidade suplementar para famílias em processo de doação de órgãos para transplantes. Rev Bras Psicodrama 2015; 23(2):75-81. 13. ABTO - Associação Brasileira de Transplantes de Órgãos. Dimensionamento dos transplantes no Brasil e em cada estado (2010-2017) [internet]. 2017 [acesso em 7 abr. 2018]. Disponível em: http://www.abto.org. br/abtov03/Upload/file/RBT/2017/rbt-imprensa-leitura-compressed.pdf 14. Silva Filho JB, Lopes RE, Bispo MM, Andrade, AP. Enfermagem e a sensibilização de famílias na doação de órgãos e tecidos para transplante: revisão integrativa. Rev Enferm UFPE [internet]. 2016 [acesso em 7 abr. 2018]; 10(6):4902-8. Disponível em: http://bases.bireme.br/cgi-bin/ wxislind.exe/iah/online/? IsisScript=iah/iah.xis\&src=google\&base=BDENF\&lang $=p$ \&nextAction $=$ Ink\&exprSearch $=30050$ \&indexSearch $=I D$ 15. Ministério da Saúde (BR). Doação e transplante de órgãos [internet]. 2017 [acesso em 7 abr. 2018]. Disponível em: http://portalms.saude.gov. br/acoes-e-programas/doacao-transplantes-de-orgaos/sobre-o-programa 16. Furlan AC, Espolado RCRT, Maziero KMC. Disposição de órgãos para transplante. Cienc Jurid Empres [internet]. 2010 [acesso em 7 abr. 2018]; 11(1):49-59. Disponível em: http://pgsskroton.com.br/seer/index.php/juridicas/article/view/966 2015

17. Pereira PM, Oliveira HM, Bertoldi PEW. Doação de órgãos: fatores que inviabilizam a doação e o papel do enfermeiro frente ao processo de captação [monografia]. Jaraguá do Sul: Faculdade Jangada; 2012. 